\title{
Study on the Association between Ambient Air Pollution and Daily Cardiovascular and Respiratory Mortality in an Urban District of Beijing
}

\author{
Fengying Zhang ${ }^{1,2}$, Liping $\mathrm{Li}^{3}$, Thomas Krafft ${ }^{1,4}$, Jinmei Lv ${ }^{1,2}$, Wuyi Wang ${ }^{1, *}$ and Desheng Pei ${ }^{3}$
}

1 Institute of Geographic Sciences and Natural Resources Research, Chinese Academy of Sciences, 11A Datun Road, Beijing 100101, China; E-Mails: fy-zhang05@hotmail.com (F.Z.); t.krafft@geomed-research.eu (T.K.); 1vyuan0403@hotmail.com (J.L.)

2 Graduate University of Chinese Academy of Sciences, Beijing 100049, China

3 Injury Prevention Research Center, Shantou University Medical College, Shantou 515041, Guangdong Province, China; E-Mails: lipingli65@gmail.com (L.L.); bailiazhu@ 126.com (D.P.) Department of International Health, Faculty of Health, Medicine and Life Sciences, Maastricht University, 6200 MD Maastricht, The Netherlands

* Author to whom correspondence should be addressed; E-Mail: wangwy@igsnrr.ac.cn; Tel.: +86-10-6488-9286; Fax: +86-10-6485-6504.

Received: 17 April 2011 / Accepted: 20 May 2011 / Published: 9 June 2011

\begin{abstract}
The association between daily cardiovascular/respiratory mortality and air pollution in an urban district of Beijing was investigated over a 6-year period (January 2003 to December 2008). The purpose of this study was to evaluate the relative importance of the major air pollutants [particulate matter $(\mathrm{PM}), \mathrm{SO}_{2}, \mathrm{NO}_{2}$ ] as predictors of daily cardiovascular/respiratory mortality. The time-series studied comprises years with lower level interventions to control air pollution (2003-2006) and years with high level interventions in preparation for and during the Olympics/Paralympics (2007-2008). Concentrations of $\mathrm{PM}_{10}, \mathrm{SO}_{2}$, and $\mathrm{NO}_{2}$, were measured daily during the study period. $\mathrm{A}$ generalized additive model was used to evaluate daily numbers of cardiovascular/ respiratory deaths in relation to each air pollutant, controlling for time trends and meteorological influences such as temperature and relative humidity. The results show that the daily cardiovascular/respiratory death rates were significantly associated with the concentration air pollutants, especially deaths related to cardiovascular disease. The current day effects of $\mathrm{PM}_{10}$ and $\mathrm{NO}_{2}$ were higher than that of single lags (distributed lags) and
\end{abstract}


moving average lags for respiratory disease mortality. The largest $\mathrm{RR}$ of $\mathrm{SO}_{2}$ for respiratory disease mortality was in $\operatorname{Lag} 02$. For cardiovascular disease mortality, the largest $\mathrm{RR}$ was in Lag01 for $\mathrm{PM}_{10}$, and in current day (Lag0) for $\mathrm{SO}_{2}$ and $\mathrm{NO}_{2} . \mathrm{NO}_{2}$ was associated with the largest RRs for deaths from both cardiovascular disease and respiratory disease.

Keywords: air pollutants; respiratory disease; cardiovascular disease; mortality; environmental exposure

\section{Introduction}

It is well established that air pollution is a major threat to human health [1-3]. Numerous time-series studies have indicated a positive association between short-term variation in ambient levels of particulate matter (PM) and daily mortality counts [4-11]. Extensive clinical, epidemiological and toxicological studies have provided evidence of the relationships between exposure to ambient concentrations and human health [12-19]. Even within the limits of the current air quality standards, the negative health effect of air pollutants can still be observed [20-22].

The association between air pollution and deaths from respiratory disease and cardiovascular disease is of general concern to epidemiological researchers $[1,23]$. In the last decade, many studies have applied time-series methods to search for associations between air pollution and its health effects [10,24-28].

Beijing, as a major metropolis and the capital of China, has a very serious air pollution problem [29-33]. Over the last 30 years, Chinese researchers in the field of environmental health have conducted a series of population studies on the relationship between ambient air pollution and the related health impacts on the people of Beijing. The concentration of PM with aerodynamic diameters less than $10 \mu \mathrm{m}\left(\mathrm{PM}_{10}\right)$, monitored by the Beijing Environmental Protection Bureau (BJEPB) from 2000 to 2004, indicated that PM was a major problem in Beijing [34]. The risk of cardiovascular mortality was estimated to increase by $11 \%$ (95\% Confidence Interval [CI]: 5-16\%) with each doubling of $\mathrm{SO}_{2}$ concentration. The association of total suspended particulates with cardiovascular mortality was positive but not significant $[4,35]$. Ambient air pollution caused adverse health effects among the exposed population in Beijing during 2000 to 2002 [36].

Most studies have focused on larger areas [6,23,24,35,37], but there has been little research using district-based cardiovascular/respiratory mortality and air pollution data to determine their potential relationship. The district level data provide further evidence on the actual health burden of the urban population by focusing on the inner city and excluding rural Beijing. Most of the earlier research was conducted in the 1990s and in 2000 to 2004 [4,35,36], research conducted during the crucial (policy relevant) period of 2005 to 2008 is still rare.

Despite considerable efforts to improve air quality, air pollution remains the single largest environmental and public health issue affecting Beijing [38-40]. The city's geographical location intensifies the problem with the surrounding mountain ranges impeding air circulation and dispersion of pollutants $[39,40]$. The extensive use of coal for providing heating to the rapidly growing population 
and the unprecedented increase in the number of motor vehicles (approaching 4.03 million vehicles registered in Beijing in February 2010) have outweighed many of the pollution control measures.

This study was undertaken to investigate the relationship between cardiovascular/respiratory mortality and the concentrations of air pollutants in the Chaoyang District of Beijing, over the 6-year period from 2003 through 2008. Chaoyang District was chosen since it is representative of the urban core of Beijing and because of the availability of cardiovascular/respiratory mortality data for the permanent residents. Our study aims for providing further epidemiological and scientific evidence for informed decisions on air pollution control measures.

\section{Materials and Methods}

\subsection{Study Area and Population}

The Chaoyang District, comprising an area of $470.8 \mathrm{~km}^{2}$, lies in the east and north east of urban Beijing. The district's population was 1.522 million people in 2000, and 1.818 million in 2008 [41]. Beijing has a sub-humid warm temperate continental monsoon climate, with annual daily mean temperature of $11.6{ }^{\circ} \mathrm{C}$, minimum mean daily temperature of $-4.6^{\circ} \mathrm{C}$ in January, and maximum mean daily temperature of $25.9^{\circ} \mathrm{C}$ in July.

\subsection{Data Source}

Mortality data. The Beijing government requires that a decedent's family obtain a death certificate from the local public health station (a hospital or a local community clinic) to remove the deceased person from the government-controlled household registration. Also, the decedent's family must submit the death certificate to the local police station to cancel the decedent's household registration (hukou); thus the decedent's family obtains two documents (one from the police station and another from the local public health station), which are required before the body can be cremated. The local public health station submits all information from the death certificates to the District Centre for Disease Control and Prevention (CDC) of Beijing. Based on this information the District Centre for CDC of Beijing maintains an electronic death registry.

All mortality data for the calendar years 2003 to 2008 were obtained from death certificates recorded at CDC of Chaoyang District. In the death registry causes are coded by the International Classification of Disease revision 10 (ICD10). For this study, all deaths from cardiovascular disease (CVD) (I00-I99) and respiratory disease (RD) (J00-J98) were identified.

Pollutants. Air quality data was provided by the Beijing Municipal Environmental Protection Monitoring Center. Daily ambient air concentrations of $\mathrm{PM}_{10}, \mathrm{SO}_{2}$ and $\mathrm{NO}_{2}$ were provided as daily mean values measured from eleven state-controlled monitoring stations in Beijing. According to the technical guidelines of the Chinese government, the location of these monitoring stations must not be in the direct vicinity of traffic intersections or of major industrial polluters and should also have sufficient distance to any other emitting source. Thus the monitoring data reflect the general background urban air pollution level in our study area.

Meteorological data. To control for the effects of weather on mortality, meteorological data (daily mean temperature, relative humidity and air/barometric pressure) were obtained from the Beijing 
Meteorological Office. The weather data were measured at a fixed-site station located in the study district. This station belongs to the Beijing Meteorological Office, the monitoring standard is consistent with international WMO standard, and the data is representative, though small variations in parts of the study area due to the urban micro-climate effect cannot be ruled out. According to the annual temperature of Beijing, we divided the season into the warm season from April to September, and the cool season from October to March (the latter is the heating season, reflected in higher concentrations of some of the air pollutants.).

\subsection{Data Analysis}

The objective of the data analysis was to quantify the association between daily mortality and daily mean air pollutant concentrations, while adjusting for weather and temporal factors in the multivariable modeling. Because the daily number of deaths was small and typically followed a Poisson distribution [28,42-44], the core analysis was a GAM with log link and Poisson error that accounted for fluctuations in daily numbers of deaths. Consistent with other time-series studies $[45,46]$, we used the generalized additive model (GAM) with penalized splines to analyze the daily counts of mortality, air pollution, and covariates (meteorological factors, time trend, and day of the week).

Before conducting the model analyses, there were two steps in the procedure of the model building and model fit: development of the best base model (without a pollutant) and development of the main model (with a pollutant). The latter is achieved by adding the air pollution variables to the final cause-specific best base model, assuming a linear relationship between the logarithmic mortality count and air pollutant concentration.

First, we constructed the basic pattern of mortality excluding the air pollution variables. We incorporated smoothed spline functions of time and weather conditions, which can include non-linear and non-monotonic links between mortality and time/weather conditions, offering a flexible modeling tool [28]. Other covariates, such as day of the week (DOW), were also included in the basic models.

After we established the basic models, we introduced the pollutant variables and analyzed their effects on cardiovascular disease and respiratory mortality. To compare the relative quality of the mortality predictions across these non-nested models, Akaike's Information Criterion (AIC) was used as a measure of how well the model fitted the data [47]. Smaller AIC values indicate the preferred model. Briefly, we fitted the following log-linear generalized additive models to obtain the estimated pollution log-relative rate $\beta$ in the study district:

$$
\log \left[E\left(Y_{t}\right)\right]=\alpha+\sum_{i=1}^{q} \beta_{i}\left(X_{i}\right)+\sum_{j=1}^{p} f_{j}\left(Z_{j}, d f\right)+W_{t}(\text { week })
$$

Here $E\left(Y_{t}\right)$ represents the expected number of deaths at day $t ; \beta$ represents the log-relative rate of mortality associated with a unit increase of air pollutants; $\mathrm{X}_{\mathrm{i}}$ indicates the concentrations of pollutants at day $\mathrm{t} ; \mathrm{W}_{\mathrm{t}}\left(\right.$ week) is the dummy variable for day of the week. $\sum_{j=1}^{p} f_{j}\left(Z_{j}, d f\right)$ is the non-parametric spline function of calendar time, temperature and humidity.

Regarding the basic models, we also did some sensitivity analysis following Qian's method [37]. We initialized the $\mathrm{df}$ as $7 \mathrm{df} /$ year for time, $3 \mathrm{df}$ for temperature and barometric pressure, $5 \mathrm{df}$ for 
humidity. We fitted both single-pollutants models and multi-pollutant models (models with a different combination of two or three pollutants per model) to assess the stability of pollutants' effect.

Further we examined the effect of air pollutants with different lag (L) structures of single day lag (distributed lag; from L0 to L2) and multi-day lag (moving average lag; L01 and L02). Here a lag of 0 day (L0) corresponds to the current-day pollution, and a lag of 1 day refers to the previous-day concentration. In multi-day lag models, L02 corresponds to 3-day moving average of pollutant concentration of the current and previous 2 days [22]. Here, the meteorological factors used in the lag models (distributed lag model, moving average model) were the current day data.

Seasonality was differentiated on the basis of heating/ no-heating periods between the warm season from April to September and October to March as cold season of Beijing with additional pollution from heating sources. Our seasonal analysis followed the method introduced in [42].

All statistical analyses were conducted in R2.9.2 using the MGCV package (R Development Core Team, 2010). The results obtained were expressed as the relative risk $\left(R R=e^{\beta x \Delta C}\right.$, where $\Delta C$ is the increased amount of air pollutants, in this study we used $10 \mu \mathrm{g} / \mathrm{m}^{3}$ for comparisons with similiar studies conducted for other places of China) of mortality per $10 \mu \mathrm{g} / \mathrm{m}^{3}$ increase in air pollutant concentrations.

\section{Results}

\subsection{Descriptive Analysis}

The distribution of deaths, meteorological factors, and air pollutants for the study district in Beijing between January 1, 2003 and December 31, 2008 (2,192 days in total) are presented in Table 1.

Table 1. Daily pollutant concentrations, meteorological factors and numbers of deaths.

\begin{tabular}{|c|c|c|c|c|c|c|c|c|c|c|}
\hline & & \multirow{2}{*}{ Mean } & \multirow{2}{*}{ Warm } & \multirow{2}{*}{ Cold } & \multirow{2}{*}{$S D$} & \multicolumn{5}{|c|}{ Percentage } \\
\hline & & & & & & Min & 25 & Median & 75 & Max \\
\hline Air pollutants & $\mathrm{PM}_{10}$ & 143.1 & 138.1 & 148.1 & 87.2 & 9.0 & 82.0 & 128.0 & 180.0 & 600.0 \\
\hline concentration & $\mathrm{SO}_{2}$ & 112.4 & 22.9 & 202.3 & 316.9 & 5.0 & 17.0 & 30.0 & 64.0 & 1643.0 \\
\hline $24 \mathrm{~h}$ mean $\left(\mu \mathrm{g} / \mathrm{m}^{3}\right)$ & $\mathrm{NO}_{2}$ & 64.8 & 58.2 & 71.5 & 24.2 & 14.4 & 49.6 & 62.4 & 78.4 & 214.4 \\
\hline \multirow{3}{*}{$\begin{array}{l}\text { Meteorological measures } \\
24 \text { h mean }\end{array}$} & Temperature $\left({ }^{\circ} \mathrm{C}\right)$ & 13.5 & 22.6 & 4.3 & 10.9 & -10.1 & 3.2 & 14.7 & 23.5 & 32.1 \\
\hline & Humidity (\%) & 52.7 & 58.5 & 46.8 & 20.2 & 8.0 & 36.0 & 54.0 & 69.0 & 97.0 \\
\hline & Air pressure $(\mathrm{hPa})$ & 1012.6 & 1004.8 & 1020.5 & 101.8 & 987.8 & 1004.5 & 1012.4 & 1020.8 & 1043.0 \\
\hline \multirow{3}{*}{ Daily deaths, mean } & Total & 22.8 & 21.1 & 24.6 & 7.2 & 6.0 & 18.0 & 22.0 & 27.0 & 54.0 \\
\hline & Cardiovascular & 10.4 & 9.4 & 11.5 & 4.0 & 1.0 & 8.0 & 10.0 & 13.0 & 27.0 \\
\hline & Respiratory & 2.2 & 1.9 & 2.5 & 1.8 & 0.0 & 1.0 & 2.0 & 3.0 & 14.0 \\
\hline
\end{tabular}

During the 6-year study period, the mean daily concentrations were $143.07 \mu \mathrm{g} / \mathrm{m}^{3}$ for $\mathrm{PM}_{10}$, $112.42 \mu \mathrm{g} / \mathrm{m}^{3}$ for $\mathrm{SO}_{2}$ and $64.83 \mu \mathrm{g} / \mathrm{m}^{3}$ for $\mathrm{NO}_{2}$, respectively. $\mathrm{PM}_{10}$ was the major air pollutant in Beijing. The average concentrations of the three air pollutants were below the Grade II national air quality limits (the $24 \mathrm{~h}$ mean concentration limit of $\mathrm{PM}_{10}$ is $150 \mu \mathrm{g} / \mathrm{m}^{3}$ [48]). However, the maximum daily mean $\mathrm{PM}_{10}$ concentration was above the Grade II and even the Grade III national air quality limits; the pollution ranges of $\mathrm{PM}_{10}$ were wide, and the upper end was higher than the recommended 
limits in this study. $\mathrm{SO}_{2}$ and $\mathrm{NO}_{2}$ also showed some extra high concentrations which exceeded the Grade II national air quality limits (the $24 \mathrm{~h}$ mean concentration limit of $\mathrm{SO}_{2}$ is $150 \mu \mathrm{g} / \mathrm{m}^{3}$ and of $\mathrm{NO}_{2}$ is $80 \mu \mathrm{g} / \mathrm{m}^{3}$ [48]) (Table 2). $\mathrm{SO}_{2}$ showed an obvious seasonal variability (Table 1), with peaks in the cold or heating season (October to March). It was also five times higher in the cold than in the warm season, because sulfur rich coal was the major energy source for heating in winter. The average concentration of $\mathrm{PM}_{10}$ and $\mathrm{NO}_{2}$ showed only small variations between the cold season and the warm season.

Table 2. Number of days/per annum with air pollutants exceeding the standard limits and annual average concentration of the pollutants.

\begin{tabular}{|c|c|c|c|c|c|c|c|c|c|}
\hline \multirow[b]{2}{*}{ Year } & \multicolumn{3}{|c|}{$P M_{10}\left(\mu g / m^{3}\right)$} & \multicolumn{3}{|c|}{$\mathrm{SO}_{2}\left(\mu \mathrm{g} / \mathrm{m}^{3}\right)$} & \multicolumn{3}{|c|}{$\mathrm{NO}_{2}\left(\mu \mathrm{g} / \mathrm{m}^{3}\right)$} \\
\hline & $\begin{array}{c}\text { Grade II } \\
(\geq 150)\end{array}$ & $\begin{array}{c}\text { Grade III } \\
(\geq 250)\end{array}$ & $\begin{array}{c}\text { Annual } \\
\text { average } \\
\text { concentration }\end{array}$ & $\begin{array}{c}\text { Grade II } \\
(\geq 150)\end{array}$ & $\begin{array}{c}\text { Grade III } \\
(\geq 250)\end{array}$ & $\begin{array}{c}\text { Annual } \\
\text { average } \\
\text { concentration }\end{array}$ & $\begin{array}{c}\text { Grade II } \\
(\geq 80)\end{array}$ & $\begin{array}{c}\text { Grade III } \\
(\geq 120)\end{array}$ & $\begin{array}{c}\text { Annual } \\
\text { average } \\
\text { concentration }\end{array}$ \\
\hline 2003 & 133 & 27 & 136.05 & 26 & 26 & 129.12 & 117 & 5 & 70.24 \\
\hline 2004 & 134 & 42 & 141.61 & 8 & 8 & 73.55 & 93 & 14 & 69.47 \\
\hline 2005 & 135 & 43 & 148.97 & 21 & 21 & 128.28 & 84 & 12 & 66.59 \\
\hline 2006 & 127 & 51 & 160.66 & 28 & 28 & 156.47 & 93 & 13 & 66.59 \\
\hline 2007 & 127 & 47 & 149.11 & 19 & 19 & 117.58 & 85 & 5 & 66.38 \\
\hline 2008 & 94 & 28 & 122.06 & 9 & 9 & 69.75 & 44 & 2 & 49.77 \\
\hline Total & 750 & 238 & & 111 & 111 & & 516 & 51 & \\
\hline
\end{tabular}

Note: Air Quality Standards: Grade I for areas such as nature reserves and other areas that need special protection. Grade II is the standard for mainly residential area, commercial areas and mixed use urban areas as well as the rural areas. Grade III standard applies to specific industrial zones [48].

Overall, the concentration of air pollutants in Beijing showed an increasing trend from 2003 to 2006, and a decreasing trend in 2007 and 2008 (cf. Table 2). But even with the slight decrease in the later years the air quality in Beijing remained in a rather serious condition. The figures for 2007 and 2008 reflect the air pollution control measures undertaken in preparation for and during the 2008 Olympics/Paralympics [49].

During our study period, the mean daily temperature and humidity were $13.46{ }^{\circ} \mathrm{C}$ and $52.68 \%$, respectively. The mean daily temperature ranged from $-10.1{ }^{\circ} \mathrm{C}$ to $32.1{ }^{\circ} \mathrm{C}$, and the mean daily humidity ranged from $8 \%$ to $97 \%$, reflecting the sub-humid warm temperate continental monsoon climate of Beijing.

Table 1 shows the distributions of the daily number of deaths from respiratory disease and cardiovascular disease. From January 1, 2003 to December 31, 2008, a total of 50,032 deaths were recorded, with 22,889 from cardiovascular disease and 4,849 from respiratory disease. On average, there were about 23 deaths per day in our study area, 10 from cardiovascular disease, and two from respiratory disease. In the seasonal-specific distribution, the number of deaths in the cold season was higher than in the warm season. 


\section{Statistical Analysis}

The Statistical Package for Social Science, SPSS18.0, was used to analyze the correlation between air pollutants and meteorological factors. Correlation statistics between air pollution parameters and meteorological factors are presented in Table 3.

Table 3. Pearson coefficients of daily deaths, air pollutants and meteorological factors.

\begin{tabular}{ccccccc}
\hline & $\boldsymbol{P M}_{10}$ & $\mathbf{S O}_{2}$ & $\mathbf{N O}_{2}$ & Mean air pressure & Mean temperature & Mean humidtity \\
\hline $\mathrm{PM}_{10}$ & 1.000 & 0.308 & 0.615 & -0.105 & 0.003 & 0.168 \\
$\mathrm{SO}_{2}$ & 0.308 & 1.000 & 0.426 & 0.248 & -0.360 & 0.056 \\
$\mathrm{NO}_{2}$ & 0.615 & 0.426 & 1.000 & 0.128 & -0.186 & 0.207 \\
\hline
\end{tabular}

$n=2,192$.

$\mathrm{PM}_{10}$ levels were significantly positively correlated with humidity, negatively correlated with mean air pressure, but had no significant correlation with mean temperature. $\mathrm{SO}_{2}$ and $\mathrm{NO}_{2}$ levels were significantly positively correlated with mean air pressure and mean humidity but were negatively correlated with mean temperature.

\section{GAM Analysis}

In the one pollutant model, we also took the lag-effect into consideration. Table 4 shows results from the single-lag day for the RR increase in mortality per $10 \mu \mathrm{g} / \mathrm{m}^{3}$ increase in air pollutants.

Table 4. Distribution of RR across lags of different pollutants for respiratory disease and cardiovascular disease death.

\begin{tabular}{|c|c|c|c|c|c|c|}
\hline \multirow{2}{*}{ Respiratory } & \multicolumn{2}{|r|}{$P M_{10}$} & \multicolumn{2}{|r|}{$\mathrm{SO}_{2}$} & \multicolumn{2}{|r|}{$\mathrm{NO}_{2}$} \\
\hline & $\mathbf{R R}$ & $95 \% \mathrm{CI}$ & $\mathbf{R} \mathbf{R}$ & $95 \% \mathrm{CI}$ & $\mathbf{R R}$ & $95 \% \mathrm{CI}$ \\
\hline Lag0 & 1.00101 & $1.00057-1.00145$ & 1.00029 & $1.00018-1.00039$ & 1.00947 & $1.00759-1.01135$ \\
\hline Lag1 & 0.99967 & $0.99908-1.00027$ & 1.00002 & $0.99992-1.00012$ & 0.99989 & $0.99828-1.00149$ \\
\hline Lag2 & 0.99883 & $0.99746-1.00020$ & 1.00049 & $1.00039-1.00059$ & 1.00203 & $1.00056-1.00350$ \\
\hline Lag01 & 1.00038 & $0.99988-1.00088$ & 1.00024 & $1.00011-1.00037$ & 1.00619 & $1.00402-1.00836$ \\
\hline Lag02 & 0.99946 & $0.99701-1.00011$ & 1.00063 & $1.00047-1.00078$ & 1.00656 & $1.00421-1.00891$ \\
\hline \multirow{2}{*}{ Cardiovascular } & \multicolumn{2}{|r|}{$P M_{10}$} & \multicolumn{2}{|r|}{$\mathrm{SO}_{2}$} & \multicolumn{2}{|r|}{$\mathrm{NO}_{2}$} \\
\hline & $\mathbf{R R}$ & $95 \% \mathrm{CI}$ & $\mathbf{R R}$ & $95 \% \mathrm{CI}$ & $\mathbf{R R}$ & $95 \% \mathrm{CI}$ \\
\hline Lag0 & 1.00164 & $1.00144-1.00184$ & 1.00022 & $0.99917-1.00127$ & 1.00271 & $1.00086-1.00457$ \\
\hline Lag1 & 1.00098 & $1.00079-1.00116$ & 1.00001 & $0.99896-1.00106$ & 0.99455 & $0.98782-1.00129$ \\
\hline Lag2 & 0.99926 & $0.99809-1.00043$ & 0.99982 & $0.99877-1.00087$ & 0.99679 & $0.99312-1.00047$ \\
\hline Lag01 & 1.00187 & $1.00164-1.00211$ & 1.00019 & $1.00012-1.00025$ & 0.99698 & $0.99200-1.00197$ \\
\hline Lag02 & 1.00096 & $1.00070-1.00121$ & 1.00006 & $0.99999-1.00014$ & 0.99508 & $0.990010-1.00015$ \\
\hline
\end{tabular}

We found that the current day effects of $\mathrm{PM}_{10}$ and $\mathrm{NO}_{2}$ were higher than that of single lags (distributed lags) and moving average lags for respiratory disease mortality. The largest $\mathrm{RR}$ of $\mathrm{SO}_{2}$ for respiratory disease mortality was in Lag02 (three days moving average lag). For cardiovascular disease mortality, the largest RR was in $\mathrm{Lag} 01$ for $\mathrm{PM}_{10}$, and in current day (Lag0) for $\mathrm{SO}_{2}$ and $\mathrm{NO}_{2}$. 
Among the three air pollutants, $\mathrm{NO}_{2}$ was associated with the largest $\mathrm{RR}$ for deaths from both cardiovascular disease and respiratory disease. Based on the results from single-pollutants models (Table 4), the largest RRs for respiratory related death were Lag0 for $\mathrm{PM}_{10}$ and $\mathrm{NO}_{2}$, and the largest RRs of cardiovascular disease mortality were $\mathrm{Lag} 0$ for $\mathrm{SO}_{2}$ and $\mathrm{NO}_{2}$; so we used the current day factors to run the multiple-pollutants models for respiratory disease mortality and cardiovascular disease mortality. The results are shown in Table 5.

Table 5. RR for a $10 \mu \mathrm{g} / \mathrm{m}^{3}$ increase in pollutant levels for respiratory disease mortality and cardiovascular disease mortality.

\begin{tabular}{cccccc}
\hline \multirow{2}{*}{ Model } & Pollutant & \multicolumn{2}{c}{ Respiratory disease } & \multicolumn{2}{c}{ Cardiovascular disease } \\
\cline { 2 - 6 } & & $\mathbf{R R}$ & $\mathbf{9 5 \%} \mathbf{C I}$ & $\mathbf{R R}$ & $\mathbf{9 5 \%} \mathbf{C I}$ \\
\hline \multirow{2}{*}{ Single } & $\mathrm{PM}_{10}$ & 1.00101 & $1.00057-1.00145$ & 1.00164 & $1.00144-1.00184$ \\
pollutant & $\mathrm{SO}_{2}$ & 1.00029 & $1.00018-1.00039$ & 1.00022 & $0.99917-1.00127$ \\
& $\mathrm{NO}_{2}$ & 1.00947 & $1.00759-1.01135$ & 1.00271 & $1.00086-1.00457$ \\
\hline \multirow{5}{*}{ Two- } & $\mathrm{PM}_{10}$ & 0.99974 & $0.99922-1.00027$ & 1.00181 & $1.00157-1.00205$ \\
pollutant & $\mathrm{NO}_{2}$ & 1.01005 & $1.00782-1.01228$ & 0.99866 & $0.99765-0.99967$ \\
\cline { 2 - 6 } & $\mathrm{PM}_{10}$ & 1.00065 & $1.00018-1.00113$ & 1.00152 & $1.0013-1.00173$ \\
& $\mathrm{SO}_{2}$ & 1.00023 & $1.00012-1.00034$ & 1.00009 & $1.00004-1.00015$ \\
\cline { 2 - 6 } & $\mathrm{NO}_{2}$ & 1.00882 & $1.00675-1.01089$ & 1.00155 & $1.00062-1.00247$ \\
Three- & $\mathrm{SO}_{2}$ & 1.00008 & $0.99997-1.00020$ & 1.00018 & $1.00013-1.00024$ \\
pollutant & $\mathrm{PM}_{10}$ & 0.99966 & $0.99913-1.0002$ & 1.00173 & $1.00148-1.00197$ \\
& $\mathrm{NO}_{2}$ & 1.00949 & $1.00716-1.01182$ & 0.99807 & $0.99603-1.00012$ \\
& $\mathrm{SO}_{2}$ & 1.00010 & $0.99998-1.00021$ & 1.00012 & $1.00007-1.00018$ \\
\hline
\end{tabular}

Note: here the RRs of single pollutant were the results of current day analysis.

We observed a significant relationship between deaths from cardiovascular/respiratory diseases and the three air pollutants in both single pollutant models and multiple pollutant models. For deaths from respiratory disease, the effects of $\mathrm{PM}_{10}$ decreased after adding $\mathrm{SO}_{2}$ and $\mathrm{NO}_{2}$ (Table 5). The effects of $\mathrm{SO}_{2}$ on respiratory disease mortality did markedly change after adding $\mathrm{PM}_{10}$ into the model. The effects of $\mathrm{NO}_{2}$ increased markedly after adding $\mathrm{SO}_{2}$ or $\mathrm{PM}_{10}$. In the three air pollutants model, both the effects of $\mathrm{PM}_{10}$ and $\mathrm{SO}_{2}$ decreased markedly, but the effects of $\mathrm{NO}_{2}$ increased.

The effects of $\mathrm{PM}_{10}$ on cardiovascular disease mortality increased when $\mathrm{NO} 2$ was added to the two pollutants model, but did not markedly change after adding $\mathrm{SO}_{2}$ into the model. The effects of $\mathrm{SO}_{2}$ on cardiovascular disease mortality decreased after adding $\mathrm{PM}_{10}$ and $\mathrm{NO}_{2}$ into the models. The effects of $\mathrm{NO}_{2}$ on cardiovascular disease mortality showed the same trend as for $\mathrm{SO}_{2}$. In the three pollutants model for cardiovascular disease mortality, the effects of $\mathrm{PM}_{10}$ increased; both $\mathrm{SO}_{2}$ and $\mathrm{NO}_{2}$ showed a decreasing trend.

$\mathrm{PM}_{10}$ concentrations had a higher effect on deaths from cardiovascular disease than on respiratory disease ones. $\mathrm{SO}_{2}$ had a similar effect both on deaths from cardiovascular disease and deaths from respiratory disease. $\mathrm{NO}_{2}$ had greater effects on respiratory disease mortality than on cardiovascular disease mortality.

The seasonal analysis results shown higher mortality risks related to $\mathrm{PM}_{10}$ and $\mathrm{SO}_{2}$ during cold times for both the respiratory disease and the cardiovascular disease than that during warm times. For 
$\mathrm{SO}_{2}$, the RRs with $10 \mu \mathrm{g} / \mathrm{m}^{3}$ increasing of concentration were higher during warm season than that in cold season (Table 6).

Table 6. RR for a $10 \mu \mathrm{g} / \mathrm{m}^{3}$ increase in pollutant levels in seasonal specified analysis.

\begin{tabular}{cccccccc}
\hline & \multicolumn{2}{c}{$\mathbf{P M}_{\mathbf{1 0}}$} & \multicolumn{2}{c}{$\mathbf{S O}_{2}$} & $\mathbf{N O}_{2}$ \\
\hline $\begin{array}{c}\text { Respiratory } \\
\text { disease }\end{array}$ & warm & 0.99903 & $0.99730-1.00076$ & 1.01648 & $1.01140-1.02157$ & 0.99510 & $0.98930-1.00090$ \\
\hline $\begin{array}{c}\text { Cardiovascular } \\
\text { disease }\end{array}$ & warm & 1.00252 & $1.00217-1.00307$ & 1.00079 & $1.00049-1.00109$ & 1.01692 & $1.01638-1.01746$ \\
\hline
\end{tabular}

\section{Discussion}

Our study combined epidemiological and environmental health science research methods to study associations between major air pollutants and deaths from cardiovascular disease and respiratory disease over a period of six years. The findings have implications for environmental and social policies in the study district and beyond. The results showed that deaths from cardiovascular disease and respiratory disease were increased on days of greater air pollution. RR estimates for $\mathrm{PM}_{10}$ in $\mathrm{Lag} 0,1,2$ and Lag01,02 were significant associated with both the cardiovascular disease mortality and the respiratory disease mortality. Particulate matters have been indentified to have effect on respiratory mortality and respiratory mortality, and several potential mechanisms have been indicated [14].

The health effects showed different lag times for various pollutants in our study (Table 4). This is in accordance with other air pollution mortality studies in the Asian region [50]. In the single pollutant model, the independent health effects of $\mathrm{PM}_{10}$ and $\mathrm{NO}_{2}$ were higher than $\mathrm{SO}_{2}$ for both respiratory disease mortality and cardiovascular disease mortality. A study conducted by $\mathrm{Xu}$ et al. found that $\mathrm{SO}_{2}$ was associated with daily mortality in Beijing [4]. With the rapid increase in the number of motor vehicles in recent years, outdoor air pollution in Beijing has gradually changed from the conventional coal combustion type to the mixed coal combustion/motor vehicle emission type. We also found that $\mathrm{PM}_{10}$ had a relationship with cardiovascular disease mortality. This was in accordance with other studies [4-7].

Significant effects were more likely to be seen during October through March than during the warm season for both disease groups. Wind speed is inversely related to air pollution levels, and rain can modify the composition of air pollutants, while sun irradiation induces photochemical modifications of several pollutants. A recent study conducted in Shanghai found that several pollutants had a more significant impact on daily hospital admissions in the cold season than in the warm season [22]. A study conducted in Hong Kong also showed similar results [50].

A 1990s study conducted by Yang et al., found significant associations between cardiovascular mortality and the three main air pollutants in the single-pollutant model [51]. An increase of $10 \mu \mathrm{g} / \mathrm{m}^{3}$ for $\mathrm{PM}_{10}, \mathrm{SO}_{2}, \mathrm{NO}_{2}$, corresponded to $1.004,1.004,1.013 \mathrm{RR}$ in cardiovascular mortality. Compared with the results of studies conducted by Xu et al. in the 1990s and Yang et al. in 2003 (Table 7), the associations between air pollutants and cardiovascular mortality showed a relative curvature, implying a reduction of the negative effects on health caused by ambient air pollution in the urban areas of Beijing in recent years [36]. Since 1998 the local government of Beijing has invested considerable 
money and implemented a host of measures and policies aimed at improving the air quality in Beijing city and its environs. Over time, the air quality has improved gradually after introduction of the following measures: coal desulfurization, changes in the public transport system and road traffic control, and change of energy use patterns. The annual levels of ambient $\mathrm{SO}_{2}, \mathrm{NO}_{2}$ and $\mathrm{PM}_{10}$ were 69, 49 and $122 \mu \mathrm{g} / \mathrm{m}^{3}$, respectively in 2008; exhibiting a reduction of $43.8 \%, 30.9 \%$ and $26.1 \%$, respectively, from the 2001 levels [36]. Higher living standards, better hygienic conditions and better medical care can reduce the number of deaths, and the control of air pollution is also likely to result in health benefits [22]. However, also as a result of the rapid increase in road traffic the air quality remains to be critical and still needs further improvement.

Compared with previous studies conducted in Europe, USA and elsewhere (Table 7), our epidemiological study, with some exceptions, reports lower coefficients in the exposure-response functions for air pollution and health effects. The health effect of $\mathrm{PM}_{10}$ on cardiovascular disease and respiratory disease mortalities was similar to that reported in the USA [52-54], The Netherlands, and Vienna, but lower than in Hong Kong [50]. This may be related to the chemical composition of PM $\mathrm{PM}_{10}$, the age of the exposed population, the citizens' sensitivity to air pollution, etc [4]. Long-term high levels of air pollution can increase the adaptability of the population. Inorganic matter is the main component of $\mathrm{PM}_{10}$ in Beijing, and has low toxicity [4]. $\mathrm{PM}_{10}$ in developed countries and regions is mainly from vehicle exhausts, which has high toxicity on human health [55].

Table 7. Comparison of RR for a $10 \mu \mathrm{g} / \mathrm{m}^{3}$ increase in pollutant concentration worldwide.

\begin{tabular}{|c|c|c|c|c|c|c|c|c|}
\hline \multirow{2}{*}{ Area } & \multirow{2}{*}{ Year } & \multirow{2}{*}{ Disease } & \multicolumn{2}{|r|}{$P M_{10}$} & \multicolumn{2}{|r|}{$\mathrm{SO}_{2}$} & \multicolumn{2}{|r|}{$\mathrm{NO}_{2}$} \\
\hline & & & $\mathbf{R R}$ & $95 \% \mathrm{CI}$ & $\mathbf{R R}$ & $95 \% \mathrm{CI}$ & $\mathbf{R R}$ & $95 \% \mathrm{CI}$ \\
\hline \multirow{2}{*}{$\begin{array}{l}\text { Beijing (current } \\
\text { study) }\end{array}$} & \multirow{2}{*}{ 2003-2008 } & CVD & 1.00164 & $1.00144-1.00184$ & 1.00022 & $0.99917-1.00127$ & 1.00271 & $1.00086-1.00457$ \\
\hline & & $\mathrm{RD}$ & 1.00101 & $1.00057-1.00145$ & 1.00029 & $1.00018-1.00039$ & 1.00947 & $1.00759-1.01135$ \\
\hline Beijing [51] & 2003 & CVD & 1.004 & $1.002-1.006$ & 1.004 & $1.001-1.008$ & 1.013 & $1.002-1.024$ \\
\hline American [53] & $1987-2000$ & CVD\&RD & 1.0024 & $1.0013-1.0036$ & & & & \\
\hline \multirow{2}{*}{ Netherlands [54] } & \multirow{2}{*}{ 1992-2006 } & CVD & 1.002 & $1.001-1.004$ & & & 1.008 & $1.005-1.011$ \\
\hline & & $\mathrm{RD}$ & 1.004 & $1.002-1.007$ & & & 1.008 & $1.003-1.012$ \\
\hline \multirow{2}{*}{ Hong Kong [50] } & \multirow{2}{*}{ 1996-2002 } & CVD & 1.0058 & $1.0014-1.0103$ & 1.0103 & $1.0021-1.0185$ & 1.0117 & $1.0061-1,0173$ \\
\hline & & $\mathrm{RD}$ & 1.0089 & $1.0036-1.0142$ & 1.0106 & $1.0006-1.0206$ & 1.0092 & $1.0025-1.016$ \\
\hline \multirow{2}{*}{ Vienna [52] } & \multirow{2}{*}{ 2000-2004 } & CVD & 1.002 & $1.0009-1.0031$ & & & 1.0046 & $1.0029-1.0063$ \\
\hline & & $\mathrm{RD}$ & 1.0035 & $1.0001-1.0069$ & & & 1.0067 & $1.0027-1.0108$ \\
\hline
\end{tabular}

The health effect of $\mathrm{NO}_{2}$ on these two disease groups in our study was also higher than in other studies conducted in America [53], The Netherlands [54], and Vienna [52], but lower than in Hong Kong [50]. $\mathrm{NO}_{2}$ is the main product of automobile exhaust fumes. The increased cardiovascular mortality risks observed in the Chinese population are similar in magnitude, per quantity of pollution, to the risk found in other parts of the World, but air pollution in China is at much higher levels in general, and the effect of pollutants on cardiovascular risk is greater than in North America or Europe. The higher toxicity of $\mathrm{NO}_{2}$ may be the results of increasing car ownership in urban areas (by the end of 2008, car ownership in Beijing had reached 2.483 million), causing the proportion of $\mathrm{NO}_{2}$ in air pollutant levels to be increased [56]. 
In our study, it was found that urban air pollution can increase cardiovascular mortality and respiratory mortality among citizens in Chaoyang District of Beijing. These findings also confirm the effects of air pollutants (particulate matters, nitrogen dioxide, sulfur dioxide) described in other studies [50,51].

Our study has some limitations. For want of more detailed data, we averaged the monitoring results of 11 official monitoring stations as the proxy for the population exposure level to air pollution. This simple averaging method may raise a number of issues, because the pollutant measurements can differ between locations and the ambient monitoring results may differ from the personal exposure level to air pollutants. The error in estimating personal exposure based on fixed site monitoring stations would tend to reduce the probability of detecting an effect and introduce bias into the air pollution exposure-mortality relationship. Further studies on personal exposure should be conducted.

It was difficult to isolate the effects of one pollutant in this specific study, because of the high correlations between the three pollutants. Further and more detailed studies are needed to clarify the findings in this one.

$\mathrm{PM}_{2.5}$ is a better indicator of air pollution and has a higher health risk than $\mathrm{PM}_{10}$ [29]. Though the $\mathrm{PM}_{2.5} / \mathrm{PM}_{10}$ ratio (ratio = concentration of $\mathrm{PM}_{2.5} /$ concentration of $\mathrm{PM}_{10}$ ) has been established in Beijing. The reported ratios varied spatially and temporally, ranging from 0.25 to 0.8 [29]. For daily concentration of $\mathrm{PM}_{2.5}$ for our time period was not available, this was a limitation when assessing the health effects of particulate matters. In summary, air pollutant levels remaining within the limits of current air quality standards in residential areas in Beijing, an apparent health effect of air pollutants can still be observed.

\section{Acknowledgments}

The authors wish to thank all the staff members at the Chaoyang District Centre for Disease Control and Prevention for their strong support of this study. Further appreciations are due to Xiaochuan Pan, and Guoxing Li, Department of Occupational and Environmental, Peking University School of Public Health for support and advice in using statistical software. We would also like to thank four anonymous reviewers for their valuable comments and suggestions. The present study was supported by the International Science and Technology Cooperation Project (2007DFC20180), and Key Projects in the National Science \& Technology Pillar Program during the Eleventh Five-Year Plan Period of China (2007BAC03A11-07). We also thank the Regulations for Chinese Academy of Sciences Visiting Professorships for Senior International Scientists (2009Z2-22).

\section{Conflicts of Interest}

All authors declare they have no conflict of interest to disclose in the context of this study. 


\section{References}

1. Brunekreef, B.; Holgate, S. Air pollution and health. Lancet 2002, 360, 1233-1242.

2. Pope, C.A.; Dockery, D.W. Health effects of fine particulate air pollution: Lines that connect. J. Air Waste Manage. Assoc. 2006, 56, 709-742.

3. Brook, R.D.; Rajagopalan, S.; Pope, C.A.; Brook, J.R.; Bhatnagar, A.; Diez-Roux, A.V.; Holguin, F.; Hong, Y.L.; Luepker, R.V.; Mittleman, M.A.; et al. Particulate matter air pollution and cardiovascular disease an update to the scientific statement from the american heart association. Circulation 2010, 121, 2331-2378.

4. Xu, X.; Gao, J.; Chen, Y. Air pollution and daily mortality in residential areas of Beijing, China. Arch. Environ. Health 1994, 49, 216-222.

5. Pope, C. Invited commentary: particulate matter-mortality exposure-response relations and threshold. Am. J. Epidemiol. 2000, 152, 407-412.

6. Dominici, F.; McDermott, A.; Zeger, S.L.; Samet, J.M. Airborne particulate matter and mortality: Timescale effects in four US cities. Am. J. Epidemiol. 2003, 157, 1055-1065.

7. Kan, H.; Chen, B. A case-crossover analysis of air pollution and daily mortality in Shanghai. J. Occup. Health 2003, 45, 119-124.

8. Laden, F.; Neas, L.M.; Dockery, D.W.; Schwartz, J. Association of fine particulate matter from different sources with daily mortality in six US cities. Environ. Health Perspect. 2000, 108, 941-947.

9. Murray, C.J.L.; Lopez, A.D. Global mortality, disability, and the contribution of risk factors: Global Burden of Disease Study. Lancet 1997, 349, 1436-1442.

10. Samet, J.M.; Dominici, F.; Curriero, F.C.; Coursac, I.; Zeger, S.L. Fine particulate air pollution and mortality in 20 US Cities, 1987-1994. N. Engl. J. Med. 2000, 343, 1742-1749.

11. Schwartz, J.; Dockery, D.W.; Neas, L.M. Is daily mortality associated specifically with fine particles? J. Air Waste Manage. Assoc. 1996, 46, 927-939.

12. Anderson, H.; de Leon, A.; Bland, J.; Bower, J.; Strachan, D. Air pollution and daily mortality in London: 1987-92. Br. Med. J. 1996, 312, 665-669.

13. Magas, O.K.; Gunter, J.T.; Regens, J.L. Ambient air pollution and daily pediatric hospitalizations for asthma. Environ. Sci. Pollut. Res. 2007, 14, 19-23.

14. Samoli, E.; Peng, R.; Ramsay, T.; Pipikou, M.; Touloumi, G.; Dominici, F.; Burnett, R.; Cohen, A.; Krewski, D.; Samet, J.; Katsouyanni, K. Acute effects of ambient particulate matter on mortality in Europe and North America: Results from the APHENA study. Environ. Health Perspect. 2008, 116, 1480-1486.

15. Laumbach, R.J.; Kipen, H.M. Acute effects of motor vehicle traffic-related air pollution exposures on measures of oxidative stress in human airways. Ann. NY Acad. Sci. 2010, 1203, 107-112.

16. Hoek, G.; Brunekreef, B.; Goldbohm, S.; Fischer, P.; van den Brandt, P.A. Association between mortality and indicators of traffic-related air pollution in the Netherlands: A cohort study. Lancet 2002, 360, 1203-1209.

17. Kunzli, N.; Kaiser, R.; Medina, S.; Studnicka, M.; Chanel, O.; Filliger, P.; Herry, M.; Horak, F.; Puybonnieux-Texier, V.; Quenel, P.; et al. Public-health impact of outdoor and traffic-related air pollution: A European assessment. Lancet 2000, 356, 795-801. 
18. Pope, C.A.; Burnett, R.T.; Thun, M.J.; Calle, E.E.; Krewski, D.; Ito, K.; Thurston, G.D. Lung cancer, cardiopulmonary mortality, and long-term exposure to fine particulate air pollution. JAMA J. Am. Med. Assoc. 2002, 287, 1132-1141.

19. Pope, C.A.; Burnett, R.T.; Thurston, G.D.; Thun, M.J.; Calle, E.E.; Krewski, D.; Godleski, J.J. Cardiovascular mortality and long-term exposure to particulate air pollution - Epidemiological evidence of general pathophysiological pathways of disease. Circulation 2004, 109, 71-77.

20. Filleul, L.; Medina, S.; Cassadou, S. Urban particulate air pollution: from epidemiology to health impact in public health. Rev. Epidemiol. Sante Publique 2003, 51, 527-542.

21. Vedal, S.; Brauer, M.; White, R.; Petkau, J. Air pollution and daily mortality in a city with low levels of pollution. Environ. Health Perspect. 2003, 111, 45-51.

22. Chen, R.J.; Chu, C.; Tan, J.G.; Cao, J.S.; Song, W.M.; Xu, X.H.; Jiang, C.; Ma, W.J.; Yang, C.X.; Chen, B.H.; et al. Ambient air pollution and hospital admission in Shanghai, China. J. Hazard. Mater. 2010, 181, 234-240.

23. Schwartz, J. Assessing confounding, effect modification, and thresholds in the association between ambient particles and daily deaths. Environ. Health Perspect. 2000, 108, 563-568.

24. Roberts, S.; Martin, M.A. Applying a moving total mortality count to the cities in the NMMAPS database to estimate the mortality effects of particulate matter air pollution. Occup. Environ. Med. 2006, 63, 193-197.

25. Schwartz, J. Harvesting and long term exposure effects in the relation between air pollution and mortality. Am. J. Epidemiol. 2000, 151, 440-448.

26. Zmirou, D.; Schwartz, J.; Saez, M.; Zanobetti, A.; Wojtyniak, B.; Touloumi, G.; Spix, C.; de Leon, A.P.; Le Moullec, Y.; Bacharova, L.; et al. Time-series analysis of air pollution and cause-specific mortality. Epidemiology 1998, 9, 495-503.

27. Dominici, F.; McDermott, A.; Daniels, M.; Zeger, S.L.; Samet, J.M. Revised analyses of the national morbidity, mortality, and air pollution study: Mortality among residents of 90 cities. J. Toxicol. Environ. Health Part A 2005, 68, 1071-1092.

28. Dominici, F.; McDermott, A.; Zeger, S.L.; Samet, J.M. On the use of generalized additive models in time-series studies of air pollution and health. Am. J. Epidemiol. 2002, 156, 193-203.

29. Chan, C.K.; Yao, X. Air pollution in mega cities in China. Atmos. Environ. 2008, 42, 1-42.

30. Hao, J.M.; Wang, L.T.; Shen, M.J.; Li, L.; Hu, J.N. Air quality impacts of power plant emissions in Beijing. Environ. Pollut. 2007, 147, 401-408.

31. He, K.B.; Huo, H.; Zhang, Q. Urbab air pollution in China: Current status, characteristics, and progress. Annu. Rev. Energy Environ. 2002, 27, 397-431.

32. He, K.B.; Yang, F.M.; Ma, Y.L.; Zhang, Q.; Yao, X.H.; Chan, C.K.; Cadle, S.; Chan, T.; Mulawa, P. The characteristics of PM2.5 in Beijing, China. Atmos. Environ. 2001, 35, 4959-4970.

33. He, L.Y.; Hu, M.; Huang, X.F.; Zhang, Y.H.; Tang, X.Y. Seasonal pollution characteristics of organic compounds in atmospheric fine particles in Beijing. Sci. Total Environ. 2006, 359, 167-176.

34. Beijing Municipal Environmental Protection Bureau. Environmental Bulletin of Beijing (2000-2004); Beijing Municipal Environmental Protection Bureau: Beijing, China, 2005. 
35. Zhang, J.L.; Song, H.Q.; Tong, S.L.; Li, L.; Liu, B.Y.; Wang, L.H. Ambient sulfate concentration and chronic disease mortality in Beijing. Sci. Total Environ. 2000, 262, 63-71.

36. Aunan, K.; Pan, X. Exposure-response functions for health effects of ambient air pollution applicable for China-a meta-analysis. Sci. Total Environ. 2004, 329, 3-16.

37. Qian, Z.; He, Q.; Lin, H.; Kong, L.; Liao, D.; Dan, J.; Bentley, C.; Wang, B. Association of daily cause-specific mortality with ambient particle air pollution in Wuhan, China. Environ. Res. 2007, 105, 380-389.

38. Guo, X.R.; Cheng, S.Y.; Chen, D.S.; Zhou, Y.; Wang, H.Y. Estimation of economic costs of particulate air pollution from road transport in China. Atmos. Environ. 2010, 44, 3369-3377.

39. Zhang, Q.H.; Zhang, J.P.; Xue, H.W. The challenge of improving visibility in Beijing. Atmos. Chem. Phys. 2010, 10, 7821-7827.

40. Hou, Q.; An, X.Q.; Wang, Y.; Guo, J.P. An evaluation of resident exposure to respirable particulate matter and health economic loss in Beijing during Beijing 2008 Olympic Games. Sci. Total Environ. 2010, 408, 4026-4032.

41. China Statistics Press. Regional Statistical Yearbook 2009; China Statistics Press: Beijing, China, 2009.

42. Peng, R.D.; Dominici, F.; Pastor-Barriuso, R.; Zeger, S.L.; Samet, J.M. Seasonal analyses of air pollution and mortality in 100 US cities. Am. J. Epidemiol. 2005, 161, 585-594.

43. Jiang, L.L.; Zhang, Y.H.; Song, G.X.; Chen, G.H.; Chen, B.H.; Zhao, N.Q.; Kan, H.D. A time series analysis of outdoor air pollution and preterm birth in Shanghai, China. Biomed. Environ. Sci. 2007, 20, 426-431.

44. Hajat, S.; Anderson, H.; Atkinson, R.; Haines, A. Effects of air pollution on general practitioner consultations for upper respiratory diseases in London. Occup. Environ. Med. 2002, 59, 294-299.

45. Peng, R.D.; Dominici, F.; Louis, T.A. Model choice in time series studies of air pollution and mortality. J. Roy. Statist. Soc. Ser. A Stat. 2006, 169, 179-198.

46. Huang, W.; Tan, J.G.; Kan, H.D.; Zhao, N.; Song, W.M.; Song, G.X.; Chen, G.H.; Jiang, L.L.; Jiang, C.; Chen, R.J.; Chen, B.H. Visibility, air quality and daily mortality in Shanghai, China. Sci. Total Environ. 2009, 407, 3295-3300.

47. Akaike, H. Statistical predictor identification. Ann. Inst. Stat. Math. 1970, 22, 203-217.

48. China National Air Quality Standard. GB 3095-1996; China National Air Quality Standard: Beijing, China, 1996.

49. Fitch, K.; Lu, Y.; Chen, T.; Ming, D.; Song, Q. Air Quality and Control. In The Health Legacy of the 2008 Beijing Olympic Games: Successes and Recommendations; Jin, D., Arne, L., Hans, T., Eds.; WHO: Geneva, Switzerland, 2008; Volume 13, pp. 107-115.

50. Wong, C.; Ou, C.; Chan, K.; Chau, Y.; Thach, T.; Yang, L.; Chung, R.; Thomas, G.; Peiris, J.; Wong, T. The effects of air pollution on mortality in socially deprived urban areas in Hong Kong, China. Environ. Health Perspect. 2008, 116, 1189-1194.

51. Yang, M.; Pan, X. Time-series analysis of air pollution and cardiovascular mortality in Beijing, China.(in chinese). J. Environ. Health 2008, 25, 294-297.

52. Neuberger, M.; Rabczenko, D.; Moshammer, H. Extended effects of air pollution on cardiopulmonary mortality in Vienna. Atmos. Environ. 2007, 41, 8549-8556. 
53. Dominici, F.; Peng, R.; Zeger, S.; White, R.; Samet, J. Particulate air pollution and mortality in the United States: Did the risks change from 1987 to 2000? Am. J. Epidemiol. 2007, 166, 880-888.

54. Fischer, P.H.; Marra, M.; Ameling, C.B.; Nicole, J.; Cassee, F.R. Trends in relative risk estimates for the association between air pollution and mortality in The Netherlands, 1992-2006. Environ. Res. 2011, 111, 94-100.

55. Dominici, F.; McDermott, A.; Zeger, S.L.; Samet, J.M. National maps of the effects of particulate matter on mortality: Exploring geographical variation. Environ. Health Perspect. 2003, 111, 39-43.

56. Langrish, J.P.; Mills, N.L.; Chan, J.K.K.; Leseman, D.; Aitken, R.J.; Fokkens, P.H.B.; Cassee, F.R.; Li, J.; Donaldson, K.; Newby, D.E.; et al. Beneficial cardiovascular effects of reducing exposure to particulate air pollution with a simple facemask. Part. Fibre Toxicol. 2009, 6, 8.

(C) 2011 by the authors; licensee MDPI, Basel, Switzerland. This article is an open access article distributed under the terms and conditions of the Creative Commons Attribution license (http://creativecommons.org/licenses/by/3.0/). 